\title{
Are Organic Standards Sufficient to Ensure Sustainable Agriculture? Lessons From New Zealand's ARGOS and Sustainability Dashboard Projects
}

\author{
Charles Merfield ${ }^{1}$, Henrik Moller ${ }^{2}$ Jon Manhire ${ }^{3}$, Chris Rosin ${ }^{4}$, Solis Norton ${ }^{2}$, Peter Carey ${ }^{5}$, Lesley Hunt ${ }^{6}$, \\ John Reid ${ }^{7}$, John Fairweather ${ }^{6}$, Jayson Benge ${ }^{3}$, Isabelle Le Quellec ${ }^{3}$, Hugh Campbell ${ }^{2}$, David Lucock ${ }^{3}$, \\ Caroline Saunders ${ }^{6}$, Catriona MacLeod ${ }^{8}$, Andrew Barber ${ }^{3} \&$ Alaric McCarthy $^{2}$ \\ ${ }^{1}$ BHU Future Farming Centre, PO Box 69113, Lincoln 7646, Canterbury, New Zealand \\ ${ }^{2}$ Centre for Sustainability, University of Otago, PO Box 56, Dunedin, New Zealand \\ ${ }^{3}$ The AgriBusiness Group, PO Box 4354, Christchurch, New Zealand \\ ${ }^{4}$ Honorary Fellow, Center for Integrated Agricultural Systems, University of Wisconsin, Madison, 1535 \\ Observatory Dr, Madison, WI 53706, USA \\ ${ }^{5}$ Land Research Services, Lincoln, New Zealand \\ ${ }^{6}$ The Agribusiness and Economic Research Unit, Lincoln University, New Zealand \\ ${ }^{7}$ Ngāi Tahu Research Centre, University of Canterbury, Private Bag 14-800, Christchurch 8140, New Zealand \\ ${ }^{8}$ Landcare Research, Lincoln, New Zealand \\ Correspondence: Henrik Moller, Centre for Sustainability, University of Otago, PO Box 56, Dunedin, New \\ Zealand. E-mail: henrik.moller@otago.ac.nz
}

\author{
Received: April 15, 2015 Accepted: July 10, 2015 Online Published: July 14, 2015 \\ doi:10.5539/sar.v4n3p158 URL: http://dx.doi.org/10.5539/sar.v4n3p158
}

\begin{abstract}
Our review concludes that organic standards need to account for a broader set of criteria in order to retain claims to 'sustainability'. Measurements of the ecological, economic and social outcomes from over 96 kiwifruit, sheep/beef and dairy farms in New Zealand between 2004 and 2012 by The Agricultural Research Group on Sustainability (ARGOS) project showed some enhanced ecosystem services from organic agriculture that will assist a "land-sharing" approach for sustainable land management. However, the efficiency of provisioning services is reduced in organic systems and this potentially undermines a "land-sparing" strategy to secure food security and ecosystem services. Other aspects of the farm operation that are not considered in the organic standards sometimes had just as much or even a greater effect on ecosystem services than restriction of chemical inputs and synthetic fertilisers. An organic farming version of the New Zealand Sustainability Dashboard will integrate organic standards and wider agricultural best practice into a broad and multidimensional sustainability assessment framework and package of learning tools. There is huge variation in performance of farms within a given farming system. Therefore improving ecosystem services depends as much on locally tuned learning and adjustments of farm practice on individual farms as on uptake of organic or Integrated Management farming system protocols.
\end{abstract}

Keywords: ecosystem services, integrated management, organic farming, sustainability indicators

\section{Introduction}

Maintaining biodiversity and other ecosystem services to sustain efficient food and fibre production is one of the greatest challenges facing humanity (Millennium Ecosystem Assessment, 2005). Efficient industrialised agriculture, powered by energy and nutrient subsidies and technology, helps secure human wellbeing by providing "provisioning services" (efficient and sustainable production of food and fibre). However it has also weakened nature's ability to deliver other key regulating and supporting ecosystem services, e.g. purification of air and water, protection from disasters, and nutrient cycling. "Cultural ecosystem services" underpin connection to place, community support, land stewardship values, local economies, transfer of knowledge, and the identity of farmers. These cultural services provide the incentives and enhance capacity to sustain and adapt coupled 
social and ecological systems. All types of ecosystem services are required to capture new opportunities and counteract challenges such as climate change, peak oil, globalisation of markets, biosecurity risks and transgenic organisms (Darnhofer et al., 2011; Pretty et al., 2010).

Market assurance and certification schemes have emerged as a global response to encourage and reward sustainable agriculture and inform consumers (Campbell et al., 2012b). Such schemes often stipulate best farming practices and many establish explicit standards, sustainability assessments, monitoring and audits that seek to future-proof ecosystem services in production landscapes. They are designed to assure consumers and regulators that the food and fibre has been produced in an ethical and sustainable way, and that foods are safe and nutritious to eat. "Organic Agriculture" is one of the very earliest and well recognised of such market accreditation schemes. There are now scores of other frameworks, standards and certification schemes that purport to enhance the economic resilience and sustainability of production. Some adopt elements of Integrated Pest Management, or more broadly 'Integrated Management', that seek to reduce and optimise the chemical applications and farm inputs in general and include whole farm management systems that promote efficient use of resources and land. They increasingly incorporate social and governance dimensions of ethical farming (e.g. good labour relations, animal welfare, and broader biodiversity care). For instance, the United Nations Food and Agriculture Organisation has recently promulgated the Sustainability Assessment of Food \& Agriculture (SAFA) in an attempt to harmonise this growing and diverse range of sustainability assessment schemes (FAO, 2013). This raises an important question that we examine in this paper: Are organic standards sufficient to secure ecosystem services in the broader way that SAFA and other frameworks are now promulgating as necessary to ensure sustainability and resilience of farming?

This paper begins by briefly reviewing some of the results of the ARGOS project, a nine-year longitudinal study of organic and other farms in New Zealand. Next we present a broad 'gap analysis' between the Organic standards and principles and the new dimensions of sustainability incorporated into the SAFA. Then we describe the New Zealand Sustainability Dashboard project as an example of a tool that could close the gaps between organic standards and IM frameworks like SAFA. We conclude by examining options for the organic movement to better protect and enhance ecosystem services and secure its premiere market position for delivering sustainable and ethical food and fibre production.

\section{Does Organic Farming Deliver More, Fewer or Different Ecosystem Services?}

The Agriculture Research Group on Sustainability (ARGOS) was a transdisciplinary project measuring the ecological, economic and social outcomes from over 96 farms in New Zealand between 2004 and 2012. The project sought well-replicated and long-term research of whole working farms from different land use intensities. It compared economic, social, environmental and farming practice outcomes between Organic, "integrated management" (IM) and "conventional" orchards and farms (Campbell et al., 2012a, b). The Organic panels were certified as following organic standards. The IM panels had adopted a market assurance scheme that incorporated several principles of best farming practice, including elements of integrated pest management and optimisation of farm inputs. The "conventional" farmers did not adhere to any collective market assurance protocols. Examination of several hundred parameters tested an overarching null hypothesis of the study: $H_{o}$ : economic, social and environmental outcomes are the same for organic, integrated management and conventional farming systems.

One commercial farm or orchard from each available farming system was chosen in each of 12 clusters for each sector ('kiwifruit, 'sheep/beef' and 'dairy') spread throughout New Zealand (Campbell et al., 2012a). Clustering ensured that soils, topography, climate, ecological constraints and rural community drivers were similar for each farming approach in a given vicinity. Spreading the clusters ensured a more representative test of the null hypothesis across several regions of New Zealand. There are no IM dairy farms and all conventional kiwifruit orchards have converted to IM in New Zealand, so only the sheep/beef sector had all three farming systems available for comparison. General Linear Modelling used a blocked design to remove the effects of cluster from statistical tests of the main effects of farming system on outcomes. The dairy farm panels were monitored before conversion of half of them to organic farming, so in that case we could use a Before-After-Control-Impact approach to test whether adoption of certified organic standards causes changes in outcomes. Sheep/beef and kiwifruit farms had converted to organic or IM farming systems long before the ARGOS study began, so any observed differences in current performance of the farms will only reflect their farming system practices if we can safely assume that sustainability indicators and performance were about the same before their conversion to organic or IM methods occurred. ARGOS therefore provided a well-replicated and relatively long-term comparison of outcomes on real working farms following different market assurance protocols with outcomes on a reference group of non-assured ("conventional") farms. 


\subsection{Provisioning Services Are Reduced on Organic Farms}

Farmers primarily tune production landscapes for efficient production of food and fibre: the key provisioning service. A consistent finding of the ARGOS project was that production per hectare of land was much reduced in organic farming. For example, dairy farms converting to organic showed a consistent decline in production (milk solids/ha) relative to conventional dairy farms over a five year period (Figure 1). The largest difference in production was observed once converting farms became certified as organic growers, with organic farms producing only $69 \%$ of that of their conventional counterparts. Milk production was already lower on converting farms before they sought organic certification. This suggests that there was something about those farming families, their land or their existing farm practices before they actually formally adopted certified organic methods that resulted in lower production. This serves a clear warning that many organic vs non-organic farm outcome comparisons may provide only quasi-experimental evidence that changes in ecosystem services including yields are caused by the organic farming practices themselves. A formal experiment would require random allocation of families and land to each panel, whereas in real life the existing orientation of the farmers or even characteristics of their land or economy may have predisposed some to go organic or IM, and others to remain conventional. Our results demonstrated that a mix of both predetermined and causally driven organic farming practice effects caused lower production because initial differences from conventional colleagues greatly increased as dairy practices consolidated and certification was conferred.

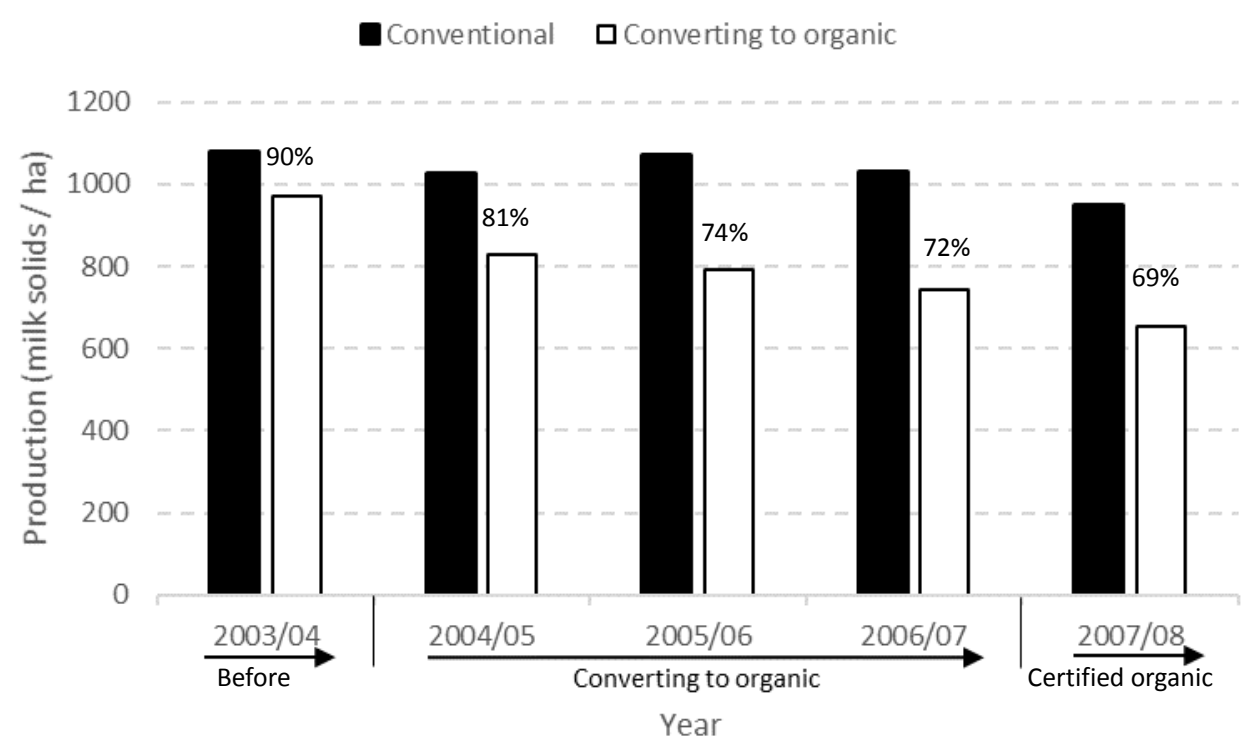

Figure 1. Annual production of dairy farms (milk solids / ha) for conventional farms and farms converting to organic, from the ARGOS project. Percentages of organic (converting to) production relative to conventional production is indicated for each year (Campbell et al., 2012a). Production measures have not been adjusted for land used to produce feed supplements imported from other farms

Comparative provisioning efficiency between sectors can best be summarised by comparing the gross energy outputs and inputs per hectare of production land. A $24.5 \%$ reduction in energy production per hectare was observed on ARGOS organic green kiwifruit orchards compared to IM counterparts, and organic sheep and beef farmers produced on average $17.5 \%$ and $29.1 \%$ less energy than their IM and conventional counterparts respectively (Norton et al., 2010). The same general pattern for reduced production per hectare has been observed in organic systems across the board when compared with more intensive agricultural systems that drive increased production by imports of ecological and energy subsidies (e.g. Sato et al., 2005; Rozzi et al., 2007). However, energy inputs (from fertilisers, pesticides, supplementary stock feed and electricity) to organic ARGOS farms were also much reduced compared to IM and conventional farms, so they rely less on ecological and energy subsidies for production. The net efficiencies of production from an energy point of view ("Energy Return on Investment", EROI) were therefore remarkably similar between all farming systems within the sheep/beef sector; but $13.4 \%$ less efficient on organic compared to conventional dairy farms; and $12.5 \%$ less efficient on organic compared to IM green kiwifruit. From an overall energy systems efficiency point of view 
then, organic ARGOS farms were of similar or slightly reduced in efficiency. However, if efficiency is calculated purely as production per hectare of land used, organic farming would be judged as a far less efficient way of delivering provisioning services.

Two broad 'land allocation' paradigms have been promulgated for provisioning a growing world human population without undermining ecosystem services: a "land-sparing" approach promotes more intensive farming of land that is tuned for maximum productivity so that more land can be protected (often reserved) for other services such as biodiversity conservation (Lindenmayer et al., 2012); a "land-sharing" approach promotes farming practices that maintain natural capital and all the ecosystem services from the same land that produces food and fibre. Along this continuum, organic agriculture is potentially less effective in a land-sparing strategy because reduced productivity on farmland may trigger more conversion of ecosystem service refuge areas to farmland or forestry. However organic farming will enhance land-sharing outcomes if it enhances regulating, supporting and cultural services in the production spaces (fields) of farming landscapes. This underscores that judgements about net benefits of organic production compared to non-organic approaches are scale dependent and coupled to an underlying land allocation model for maintenance of ecosystem services. More research is needed to test whether lower production on organic farms indeed reduces land-sparing, or whether any such environmental deficit is more than made up for in biodiversity benefits from land-sharing .

\subsection{Enhancing Biodiversity for Supporting and Regulating Cultural Services}

Organic farming standards traditionally concentrated on: prohibiting the use of xenobiocides and xenobiotic chemicals as inputs into food; only allowing naturally occurring (eobiotic) fertilisers (synthetic nitrogen fertilisers are thus prohibited) and other "inputs"; banning transgenic and similar technologies and their products; increasingly restricting nanotechnology, within a framework that is focused on enhancing soil health and maintaining the 'wholeness' of food thus produced. There is now a substantial body of research showing that this can affect the abundance of pests, weeds and beneficial biodiversity in direct ways. ARGOS found a greater variety of plants growing under shelterbelts (Moller et al., 2007) and higher species richness and abundance of invertebrates within the production areas (eg. Todd et al., 2011) of Organic compared to IM Kiwifruit orchards. Higher numbers of predators, parasitoids, herbivores, fungivores and omnivores in the organic orchards compared with those under IM are expected to result in more resilient ecosystem services in the organic orchards. The emergence of indirect effects in ecological food webs is of particular interest: might enhanced biodiversity or other ecosystem changes sufficiently substitute for the regulation services normally provided by chemical applications on conventional and IM farms? If so, more biologically efficient, inexpensive, practical and safe production can be expected from organic farming.

Biodiversity makes ecological systems adaptable and resilient to biophysical changes in production landscapes by supporting and regulating ecological processes needed for production of food and fibre. Community ecology has repeatedly emphasised that some species ('keystone species') have inordinate effects on other species in food webs, and some ('ecosystem engineers') are pivotal in creating habitat for whole new foodwebs and ecological processes. For example, earthworms comprise a major component of the animal biomass (non microbial) in soils and contribute to a range of ecosystem services through pedogenesis, development of soil structure, water regulation, nutrient cycling, assisting primary production, climate regulation, pollution remediation and cultural services (Kopke, 2015, this volume). The ARGOS study revealed higher earthworm density in organic kiwifruit orchards, but there was no evidence of them differing between farming systems for the dairy or sheep \& beef sectors (Figure 2). 


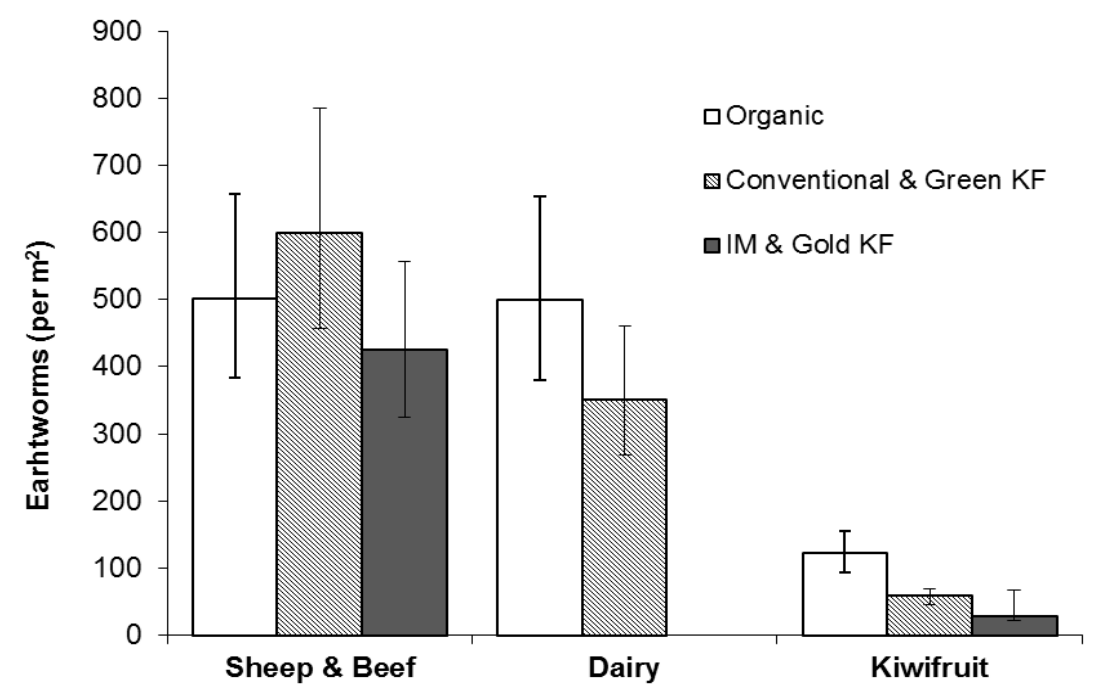

Figure 2. Earthworm density under different management systems for 36 sheep/beef, 24 dairy and 36 kiwifruit farms. Note that 'integrated management' was not available for the dairy farming sector and both Green and Gold Kiwifruit were grown under IM protocols. The error bars depict \pm 1 standard error (Sources: after Carey et al., 2010)

The ARGOS project assessed whether orchards managed under an organic system supported higher bird density and diversity than those under two different IM systems (Gold and Green Kiwifruit). Birds were researched because they are often 'top predators' in food chains (and thereby sensitive to ecosystem change), relatively easy to monitor, conspicuous and loved by many consumers. This makes them potential "Market Flagship" species for promoting sustainable farming practices and ethical purchasing by consumers (Meadows, 2012). Higher densities of all New Zealand native bird species (insectivores and nectar-feeders) were detected on orchards managed under organic systems, relative to IM orchards (MacLeod et al., 2012). This lends support to the hypothesis that organic farming systems sustain enhanced biodiversity compared to non-organic counterparts (Bengtsson, Ahnstrom \& Weibell, 2005; Hole et al., 2005). However the introduced bird species were an order of magnitude more abundant on the orchards than native species and there was no evidence that their abundance differed between farming systems. The New Zealand public have an overwhelming preference for conserving native and endemic species rather than introduced ones, mainly because the native biota are closely embraced as part of New Zealand's national identity and conservation responsibilities. However European consumers of New Zealand produce may be most concerned by the support of their own threatened farmland species that have been introduced to New Zealand and flourish there. This demonstrates a need for a more nuanced focus on particular biodiversity that might have particular functional roles or particular biocultural significance in agriecosystems rather than a simple binary expectation that organic agriculture enhances biodiversity across the board.

\subsection{A Need to Manage More Than Farming Inputs}

The above examples from the ARGOS project lead us to emphatically endorse the calls by Barberi (2015, this volume) and Niggli (2015, this volume) to focus on functional biodiversity. But we go much further to stress that further enhancement of sustainability of organic agriculture depends on finding and then managing the drivers of variation in those important animals and plants and key social-ecological systems processes. For example, pesticide loadings and woody vegetation cover proved to be more influential predictors of native bird densities than 'management systems' on New Zealand kiwifruit orchards: native bird density was lower where more pesticides were applied and higher on orchards with more woody vegetation (MacLeod et al., 2012). The presence of woody vegetation, while not considered in organic standards, provide vital ecological refuges and habitat for native New Zealand biota (Moller et al., 2008). We expect a synergistic interaction where the benefits of low toxicity of farm inputs will lift the average native bird abundance all the more above that of its non-organic counterparts if diverse and extensive woody vegetation is also retained. If organic farming actively promoted or even required provision of more woody vegetation on farms and orchards, we predict even higher density of birds would be found on organic farms. Another ARGOS example concerned spiders and beetles that 
provide important ecosystem services on dairy farms. Organic dairy farms and fenced shelterbelts supported $40 \%$ and $67 \%$ higher densities of spiders than conventional dairy farms and unfenced shelterbelts, respectively (Fukuda et al., 2011). Shelterbelts of native plant species supported higher species richness of native spiders and beetles than shelterbelts of exotic plants. So conversion to organics lifts biodiversity to some degree, but a combination of organic methods, fencing off shelterbelts and planting more native tree species in shelterbelts will provide all the more ecosystem services and biodiversity conservation on New Zealand dairy farms.

\subsection{Sustainable Intensification: Might Organic Farming Be Particularly Beneficial in More Intensive Agriculture?}

There is a clear need to transcend research from simple tests for significant differences in outcomes from organic, IM and conventional farming to testing larger scale hypotheses about the size, direction and reason for differences in ecosystem services between farming systems. An example is to test whether aspects of organic farming ameliorate the unwanted effects of landuse intensification. The ARGOS team proposed a second meta-hypothesis $H_{1}$ : Differences in economic, social and environmental outcomes between organic, integrated management and conventional farming are greater for more intensive farming sectors and farms. This emerged from ecological first principles - the higher the rate of application of ecological subsidies (i.e. anthropogenic subsidies of materials from outside an ecosystem's boundary, Pilati et al., 2009) such as artificial fertilisers and suplementaty feed for livestock, the greater the alteration of local ecology through immediate and direct ecological disturbance effects. Organic restrictions might lessen the force of such subsidies partly by their more benign nature and partly indirectly because organic farms are generally less intensive operations (reduced stocking rates, less extraction of nutrients and materials, lower productivity as seen in Figure 1 and EROI comparisons).

We had insufficient replication of sectors to fully test this intensification hypothesis, but preliminary observations are consistent with it. For example, the relative effect of farming system on earthworm abundance was much greater in the most intensive sector (Kiwifruit) than the next most intensive farming (dairy), and there was no evidence of a difference between systems in the least intensive sector (sheep \& beef). Similar interactions between sector intensity and soil structure and its macronutrients were observed (Carey et al., 2010). Rudimentary binary comparisons of organic and non-organic outcomes abound in the literature, but so far they have not led on to testing higher order drivers why these differences occur, or why they are larger in some agriecosystems than in others. Halberg (2015, this volume), Vaarst (2015, this volume) and Heckman (2015 this volume) have all empahsised the need for 'eco-functional intensification'. If the ARGOS intensification meta-hypothesis is true, organics has special value in supporting ongoing intensification of agriculture without damaging ecosystem services.

\subsection{Organic Agriculture As an Agent for Change: A Role for Cultural Services}

Our analysis thus far has mainly concerned ecological dimensions of ecosystem services. However discovery of the social and economic drivers of farming practice are also fundamentally important for sustaining coupled social-ecological systems (e.g, Rosin et al., 2008, Campbell et al., 2012b). The long term resilience and sustainability of agriculture depends on learning and adapatability (Vogl 2015, this volume). Transformation of agriculture to protect and enhance ecosystem services will depend on direction, motivation, "opportunity to perform" and ability (Tuuli, 2012; CEO Group, 2015). This means that farmers and policy makers will need an awareness of the need to change, the values and motivation to act in beneficial directions, and the capacity to make the required changes. Cultural ecosystem services include the nonmaterial benefits people obtain from ecosystems through spiritual enrichment, cognitive development, reflection, recreation, and aesthetic experiences (Millenium Ecosystem Assessment, 2005). We consider cultural services as potentially crucial for underpinning adaptability by building a sense of place and responsibility to other places and people, knowledge of the need and options for change, and forming core values to motivate change or strike balances and trade-offs between short term economic rewards and land care.

The ARGOS researchers used both formal Qualitative Analysis methods of semi-structured interviews and nationwide questionaniares (Fairweather et al., 2009a) to explore individual farmers' economic, social and environmental orientations (Table 1). Organic farmers displayed a much broader social and environmental 'breadth of view', were more likely to innovate, and were less focussed on economic success than their non-organic counterparts (Table 1). All these differences will make organic growers more aware of threats and opportunities for sustainability, and perhaps more ready to change when needed. 
Table 1. Relative orientations of organic and non-organic farmers to four aspects of farming. A score between +1 (strong support) to - 1 (strong aversion) was determined by a Factor Analysis of each farmers' answers to a nationwide survey. (Sourced from Hunt et al., 2011).

\begin{tabular}{llll}
\hline Orientation & $\begin{array}{l}\text { Non-organic } \\
(\mathbf{n = 3 3 8 )}\end{array}$ & $\begin{array}{l}\text { Organic } \\
(\mathbf{n = 1 5 7 )}\end{array}$ & t-Test significance \\
\hline $\begin{array}{l}\text { Economic Focus (relative importance } \\
\text { of economic success of their farm) }\end{array}$ & +0.07 & -0.15 & 0.034 \\
$\begin{array}{l}\text { Social Breadth of View (relative } \\
\text { contribution of their farming to wider } \\
\text { society benefits) }\end{array}$ & +0.17 & +0.37 & $<0.001$ \\
$\begin{array}{l}\text { Environmental Breadth of View } \\
\text { (relative importance to consider effects } \\
\text { of their farming beyond their own } \\
\text { land) }\end{array}$ & +0.16 & \\
$\begin{array}{l}\text { Innovation Likelihood (relative } \\
\text { willingness to experiment with their } \\
\text { farming practice) }\end{array}$ & & & \\
\hline
\end{tabular}

\section{What Should Organic Farming Be Compared Against?}

Much of the literature on organic agriculture presents binary comparisons of organic farming outcomes and their provision of ecosystem services compared to non-organic farming. The ARGOS results that we briefly summarised above emphasise the danger in such simplified binary comparisons: a rapidly growing group of IM farmers are adopting market accreditation and monitoring schemes to fine-tune their farming practice in ways that purport to be more sustainable. Outcomes from these IM growers are sometimes quite different from so-called "conventional' farmers. For example, in the ARGOS project, macoinvertebrate communities and ecosystem functioning were negatively impacted in streams running through conventional sheep/beef farms, but there was no evidence of them being different in Organic and IM farms (Magbanua et al., 2010).

The results of qualitative analysis of interviews (Campbell et al., 2012b) and the responses of IM, Organic and Conventional growers in a nationwide survey to questions about environmental, social and economic dimensions of farming sustainability (Figure 3) both emphasised that IM growers are different from conventional ones. The IM growers were not just intermediate between organic and conventional (had they been, the multidimensional scaling diagram would have approximated E in Figure 3). Instead they viewed farming in very different ways from both conventional and organic growers. Differences between the panels were relatively less for financial and social orientations (the same conclusion is demonstrated in Table 1), but organic farmers were particularly distinct in orientation to environmental and production concerns. We do not know what drives the differences already evident nor, potentially more crucially, how they might change in future because of the engagement of IM farmers in the market accreditation and sustainability best practice monitoring frameworks. Clearly there are many clusters of "greeness" in orientation within all types of farming approaches and the way these are influenced by market accreditation and reward is an important dynamic for guiding the way the organic movement positions itself in markets and as environmental friendly farming advocacy (Fairweather et al., 2009b; Campbell et al., 2012b). In the meantime we urge researchers and market advocates of organic agriculture to not simply lump all non-organic farmers into one pool, especially since the eco-verification and wider sustainability claims of the IM farmers could undermine the premiere and historical monopoly of market assertions that organic agriculture certification gaurantees sustainable and ethical production.

\section{On What Basis Should Stakeholders Compare Sustainability of Farming Systems?}

In view of the rapidly rising prominance of the IM and market assurance farming protocols that are making sustainability claims, we sought to measure the degree of congruence and divergence between their tenets for ensuring sustainability and those incorporated into organic farming. The organic 'brand' is now synonymous with the organic standards, i.e., the 'rules' of organic farming systems. Traditionally organic sustainability claims are therefore based primarily around assumption that restricting the nature of farm inputs will protect and enhance ecosystem services and produce safer and higher quality food and fibre within a more ethical production system. More recently the standards have been mapped to and endorse four core 'IFOAM principles' (IFOAM, 
2005): Health - Organic agriculture should sustain and enhance the health of soil, plant, animal, human and planet as one and indivisible; Ecology - Organic agriculture should be based on living ecological systems and cycles, work with them, emulate them and help sustain them; Fairness - Organic agriculture should build on relationships that ensure fairness with regard to the common environment and life opportunities, and; Care Organic agriculture should be managed in a precautionary and responsible manner to protect the health and well-being of current and future generations and the environment. A comprehensive summary of the standards and principles (which we will henceforth collectively refer to as 'organic norms') is found in the Common Objectives and Requirements of Organic Standards (COROS). We chose to compare organic standards and principles with the FAO's SAFA framework because the latter is a recent, comprehensive and broadly applicable set of sustainability principles that attempts to integrate the features of a large number of IM and market assurance approaches.

\subsection{How Many of SAFA's Sustainability Criteria Are Covered by Organic Principles?}

We searched for a match between each SAFA indicator and its description with the IFOAM 2014 and BioGro New Zealand organic standards. A five point mark ranging from $0 \%$ (no correspondence), $25 \%, 50 \%, 75 \%$, to $100 \%$ (complete correspondence) was scored for each SAFA indicator. Scoring was conducted by the lead author who has 24 years' experience of working with organic standards internationally to help make it as consistent and accurate as possible.
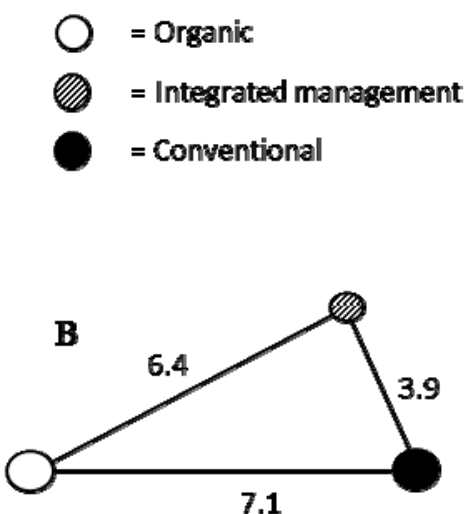

7.1

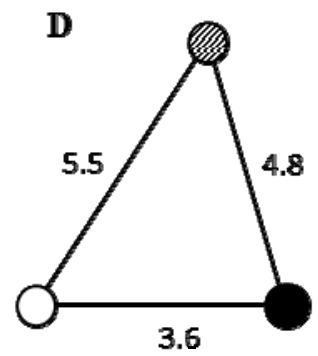

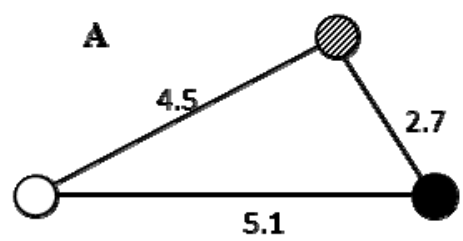

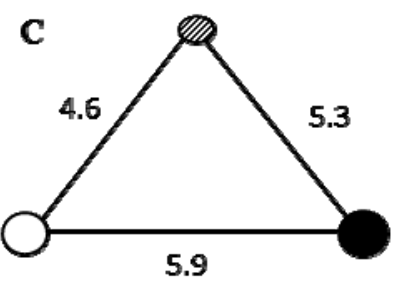

5.9

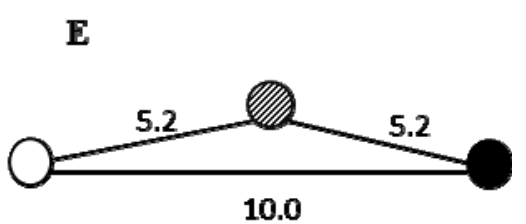

Figure 3. Multidimensional scaling to measure differences in the way New Zealand organic, IM and conventional farmers answered questions about different dimensions of farming. The numbers on each diagram are 'multivariate distances', a measure of how distinct the farmers from each farming system were in the responses to the same questions A: Production performance (9 questions), B: Environmental performance (17 questions), C: Social indicators (14 questions), D: Financial indicators (11 questions). E: a hypothetical example of IM as an intermediary between organic and conventional farming systems. (Source: The questionaire results are described by Fairweather et al. 2009a, and the multidimensional scaling is an unpublished analysis by Lesley Hunt)

Figure 4 replicates the radar charts that are commonly used by SAFA to depict performance at each spoke of a "wagon wheel" that depicts a family of criteria required for sustainability. The inner red zone represents failure of compliance when used in real SAFA assessments, but in our case we use it to show $0 \%$ congruence of the organic standards with SAFA requirements. We equate the inner and outer margins of the next amber zone with 
$25 \%$ and $49 \%$ congruence, and so on outwards until $100 \%$ congruence is plotted against the outer margin of the deep green zone around the wheel's perimeter. The dark line in Figure 4 represents average congruence of organic standards for several indicators within each SAFA sustainability dimension.

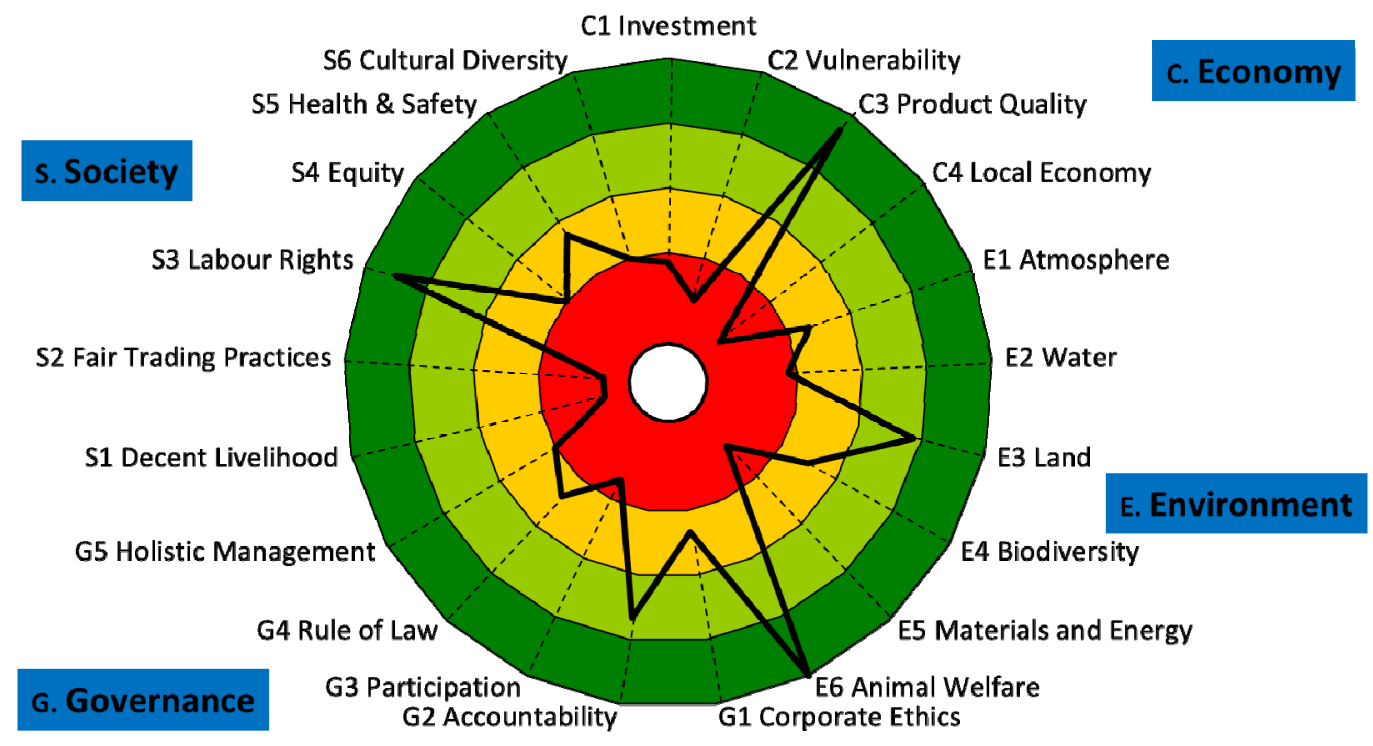

Figure 4. Sustainability scores of the organic standards when using FAO's SAFA criteria for sustainable food and fibre production. The black line indicates the degree of congruence between organic and SAFA sustainability criteria (the further the black line is from the centre the greater the congruence). Successive zones indicate grades of sustainability performance from deep green (most sustainable) around the outside to red (least sustainable) in the inner core. The SAFA framework has been customised to better meet New Zealand conditions by the Sustainability Dashboard

The organic standards are almost completely in agreement with SAFA on issues of Product quality \& information, Animal welfare and Labour rights; but organic standards are virtually silent on the need for Fair Trade, providing a decent livelihood, contributing to local economy and minimising reliance on materials and energy. Even aspects of environmental and land care (like biodiversity, water and atmosphere) that are explicitly required in SAFA assessments are only partially embraced by the organic standards.

Our overall average score for congruence (the average distance of the dark line from the centre of Figure 4) was $36 \%$. It is important to remember that just because the organic standards do not fully cover a given sustainability criterion (and so score $0 \%$ or $25 \%$ if partially covered), many of the organic farms may nevertheless be performing very well on that dimension of sustainability (indeed our ARGOS examples in Figures 1-3 and Table 1 above suggest this is the case). Our aggregated score would only measure performance if the organic farm was fully achieving the explicit requirements of organic standards and no more. The comparatively low overall score simply emphasises that SAFA and many similar sustainability assessments are including a much wider set of necessary and quite explicit conditions than those required for meeting organic standards and principles.

There is a remaining emphasis on organic input restrictions: $47 \%$ of 90 COROS standards are framed in terms of farming input restrictions, $35 \%$ concern more general principles and outcomes, and $18 \%$ regulate internal consistency of the organic standards. The IFOAM principles are cast in such general and abstract terms that they are difficult to interpret and judge in terms of day-to-day farming decisions, whereas rules on organic farm input restrictions are precise, measureable and voluminous. For example, BioGro NZ, one of the two New Zealand export organic certifiers, covers the six COROS items on fairness, respect and justice, equal opportunities and non-discrimination in just a third of a page (132 words) of its 2011 certification standards, yet the "Directory of BioGro Certified inputs for producers" 2011 for facility management, dairy, crops, bee keeping, livestock soil 
and seeds, lists 251 different types of inputs, with some inputs having multiple individual approved suppliers, e.g., fish fertilisers list 88 different fish fertiliser products, with the directories covering 26 pages. AsureQuality, the other organic certifier in New Zealand, did not include a section on social justice until its 2013 (No 5) version of its standards and devotes just $317(0.7 \%)$ words out of 43,782 to social justice.

\subsection{How Many of the Organic Standards Are Covered by the SAFA Sustainability Criteria?}

We then used the same scoring methods to perform the reverse comparison: how well would a farmer that is fully meeting SAFA performance criteria score if judged against organic standards? Standards do not have the equivalent of SAFA indicators. Instead they are more akin to a legal document with a large number of specific details. Therefore the COROS were used to undertake the comparison. COROS, also called the "The IFOAM Standards Requirements", is designed for use in international equivalence assessments of organic standards and technical regulations and provides the basis for assessing equivalence of standards for inclusion in the IFOAM Family of Standards.

For each 'Objectives and Requirements' in COROS we estimated that a fully compliant SAFA farmer would on average meet $74 \%$ of the organic norm requirements. An excellent non-organic farmer, according to SAFA criteria, performs well in terms of the requirements for organic farmers to be systems oriented, minimise pollution and land degradation, protect animal welfare and health, and act with fairness and respect (Figure 5). However, more stringent requirements on organic farmers for long-term and biologically-based soil management, avoiding synthetic inputs, and especially in avoiding unproven and unnatural technologies remain as points of difference in organic farming (Figure 5). These points of difference are reflected in very specific requirements for organic growers to avoid transgenic organisms, irradiation, certain breeding technologies and nanotechnology (Figure 6).

\section{A Need for Integrated Sustainability Assessments of Organic Farming}

In 2012, the ARGOS project received funding from the NZ Government Ministry of Business, Innovation and Employment (MBIE) and several industry co-funders to develop a New Zealand Sustainability Dashboard for primary sectors (Manhire et al., 2013). This change of direction was to assist New Zealand farmers to measure and report across a rapidly expanding set of sustainability criteria incorporated into market assurance and monitoring schemes, and partly to bridge the gap between organic standards and such schemes (Figure 4-6). However, our change of emphasis was also driven by realisation that no one farming system would deliver hugely advanced sustainability or ecosystem services compared to any other. We were more struck by the large variation in sustainability outcomes between individual ARGOS farms within the same farming system panel than in relatively slight shifts in the average performance of each panel. Lifting the overall sustainability and resilience of New Zealand agriculture will depend more on assisting all farmers to do better, not from advocacy of a single farming system approach as a one-size-fits-all solution to the challenges and opportunities for future farming. Our goal was to create a practical, locally and globally relevant package of tools to turn compliance and auditing requirements into a learning opportunity for farmers and agricultural processors.

Internationally recognised frameworks and their key generic sustainability performance indicators have been co-opted to ensure that overseas consumers can benchmark and verify the sustainability credentials of New Zealand exported products. It is a participatory, industry-led approach to measuring and reporting sustainability allowing farmers to log mainly self-assessed sustainability measures into an online network. The Sustainability Dashboard will allow for instant benchmarking, trend analysis, progress towards targets and provide warnings when trigger points indicate a need for intervention. The Dashboard will also be equipped with an automated reporting system to benchmark a participating farmer's performance with that of others producing similar goods, or using similar farming technologies (eg. irrigation). The overarching framework developed in this project closely aligns with the SAFA sustainability goals and criteria but the emphasis of different parts of the assessment is adjusted to tune to New Zealand ecological, social, economic, and governance constraints and opportunities. Relatively standardised measures of farming performance will be shared between farmers, industry advocates, policy makers and consumers. A basic version of the dashboard is currently being customised and extended to meet the needs of New Zealand organic growers in particular so that organic producers can formally measure and demonstrate their performance against many of the sustainability criteria demanded by competing market assurance programmes as well as those needed for BioGro organic certification.

\section{Conclusions: Are Organic Standards Sufficient to Ensure Sustainable Agriculture?}

Organic agriculture often leads to enhanced ecosystem services, as emphasised by several papers in this special journal issue (Delate et al., 2015; Abbott, 2015; Cambardella, 2015) and our selection of examples from the ARGOS project (Figure 2, Table 1). This will assist land-sharing approaches to multifunctional agriculture which 
can be safely assumed to promote sustainability and agricultural systems resilience. However, productivity of organic farming is often reduced compared to IM and conventional farming and this could undermine land-sparing approaches to achieving global food security while conserving ecosystem services over larger spatial scales. Some indicators of ecosystem service were relatively unchanged between farming systems, probably in part because other ecological, social, economic or governance constraints trump the effects of organic input restrictions. Provision of ecological refuges, reduced reliance on ecological subsidies, specific farming decisions like fencing shelterbelts or planting native rather than introduced trees have strong positive impacts on ecological ecosystem services, but are not part of the standards and specific requirements of organic certification. More generally, our gap analysis emphasises that organic standards only cover less than half of the broader social, economic and governance criteria for sustainability of any food and fibre production system. In contrast, farmers performing well according to accepted sustainability criteria (i.e. SAFA) would cover the majority of the organic farming requirements. Agriculture is a complex and adaptive system that responds to coupled social, ecological, economic, and governance feedbacks. It seems obvious that simple adherence to organic input restrictions and standards cannot possibly be sufficient in itself to secure sustainability and resilience. Input restrictions remain the predominant tenets of the organic standards, but wider organic principles have recently been incorporated. Current developments of the concept of Organic 3.0, which includes an attempt to demand that organic farms should demonstrate a degree of continuous development vis-à-vis the principles and goals rather than just comply with rules (IFOAM 2015), is a valuable step in this direction. We encourage strenuous promulgation of these valuable general organic principles to dispel a general and outdated notion amongst growers, policy makers and customers that organic farming is simply about restriction of certain types of potentially dangerous farm inputs. We are not advocating that organic farmers become entirely like their IM counterparts - it is vital that the organic movement retains its certified points of difference that underpin price premiums and philosophy - but we do urge organic growers to adopt the best of the IM approaches that do not compromise organic principles.

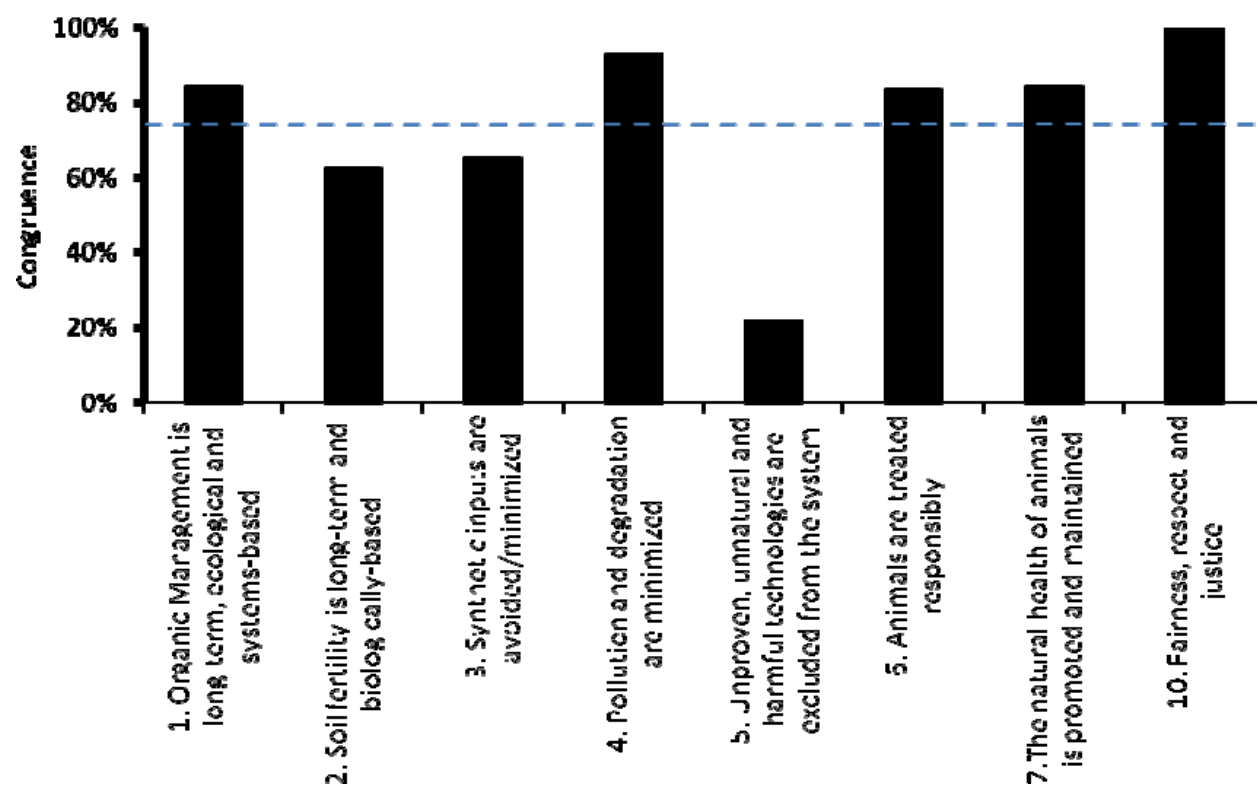

Figure 5. Congruence scores in higher order themes of a producer that is fully compliant with FAO's SAFA when judged against the IFOAM organic standards. The dashed line indicates the average degree of congruence (74\%) for 78 specific requirements of organic production 


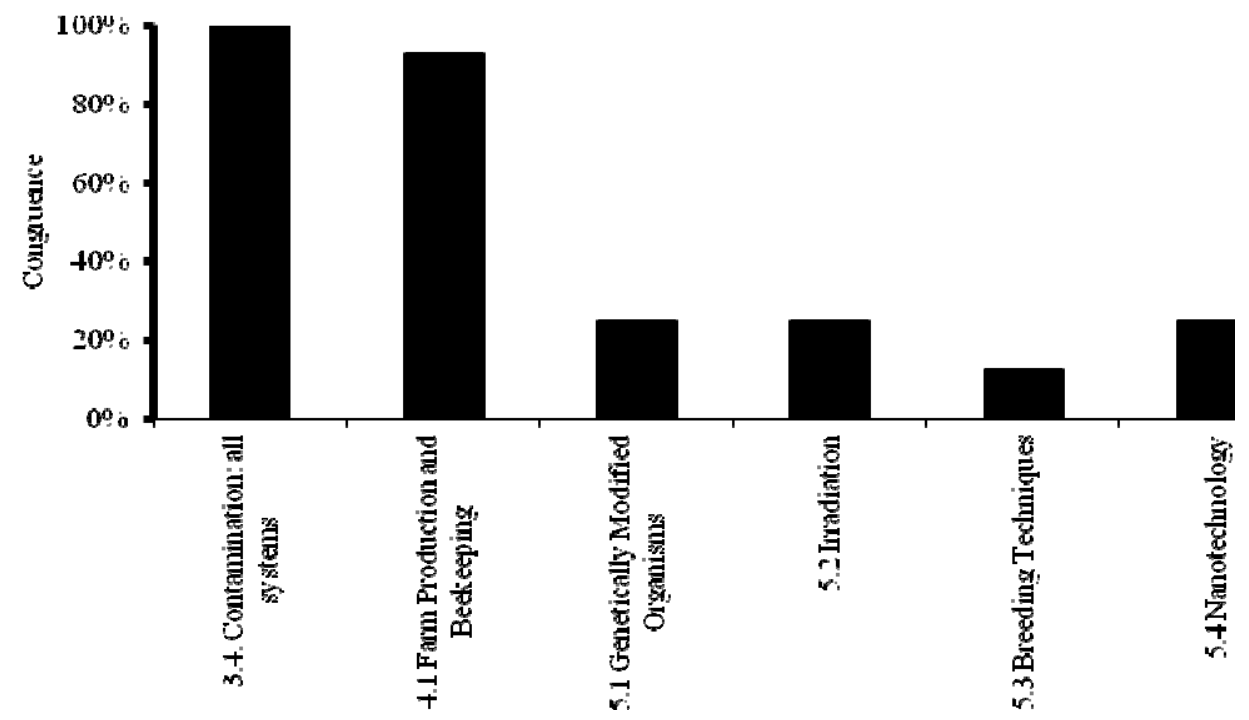

Figure 6. Congruence in some selected detailed criteria of a producer that is fully compliant with FAO's SAFA when judged against the IFOAM organic standards

This broadening of emphasis and an organic market share defence strategy could direct best farming practice, monitoring and reporting across a wider set of sustainability criteria than simply compliance with the existing organic standards. Many of the broader criteria that are now being included in general agricultural sustainability and resilience assessments will support, and be supported by, the organic principles, even though they are not explicitly codified in the standards. Some form of 'Organics Plus' eco-verification to match the claims of green market assurance programmes could help organic growers challenge and learn from IM approaches. Each version of the New Zealand Sustainability Dashboard is hosted by a particular agricultural sector that will adjust their emphasis and investment in measuring performance to match their own particular opportunities and challenges. An organic production dashboard could therefore emphasise points of difference in organic farming methods, especially strategy to minimise risk by restricting the nature of farm inputs, while still measuring the comparative performance of organic farming on the additional dimensions demanded by other market competitors. We conclude that adherence to organic standards undoubtedly promises some gains in ecosystem services, including the crucial cultural ones that assist systems adaptability and learning - but we also assert that organic standards will need to be combined with more targeted farming systems interventions across multiple criteria to maximise sustainability of organic farming.

Until detailed measurement of the comparative performance of IM and organic farming over this wider set of criteria are tabled, it is impossible to judge whether the beneficial effects of restriction to organic inputs more than outweighs the benefits of applying a wider range of sustainability interventions while still allowing chemical inputs and similar technologies on IM farms. However, we are not advocating just another round of binary comparisons of outcomes from organic and IM farming, nor from IM and conventional farming. A safer and globally more effective approach is to find local solutions for raising ecosystem services of all farms, be they organic, IM or conventional. Systematic and targeted measurement of key agricultural ecosystem drivers, will provide feedback to enable individual farming families to locally tune their farming practices for efficient and profitable production while leaving the land fit for future generations' survival and enjoyment.

\section{Acknowledgements}

The Sustainability Dashboard project is primarily funded by New Zealand's Ministry of Business, Innovation \& Employment (contract AGRB1201), with additional co-funding from BioGro New Zealand, Zespri and Kiwifruit packhouse and orchard management companies, New Zealand Wine, and Te Rūnanga o Ngāi Tahu. We thank the OECD for funding to present our research findings at the Organic Food Systems for Sustainable Production and Enhanced Ecosystem Services symposium. We thank two anonymous reviewers for help suggestions on how to improve the manuscript. 


\section{References}

Abbott, L. K., \& Manning, D. A. C. (2015). Soil health and related ecosystem services in organic agriculture. Sustainable Agriculture Research, 4(3), 116-125. http://dx.doi.org/10.5539/sar.v4n3p116

Bàrberi, P. (2015). Functional biodiversity in organic systems: The way forward? Sustainable Agriculture Research, 4(3), 26-31. http://dx.doi.org/10.5539/sar.v4n3p26

Bengtsson, J. T., Ahnstrom, J., \& Weibell, A. C. (2005). The effects of organic agriculture on biodiversity and abundance: a meta-analysis. Journal of Applied Ecology, 42, 261-269. http://dx.doi.org/10.1111/j.1365-2664.2005.01005.x

Cambardella, C. A., Delate, K., \& Jaynes, D. B. (2015). Water quality in organic systems. Sustainable Agriculture Research, 4(3), 60-69. http://dx.doi.org/10.5539/sar.v4n3p60

Campbell, H., Fairweather, J., Manhire, J., et al. (2012a). The Agriculture Research Group On Sustainability Programme: a longitudinal and transdisciplinary study of agricultural sustainability in New Zealand. ARGOS Research Report No. 12/01. 123 + xi pp.

Campbell, H., Rosin, C., Hunt, L., \& Fairweather, J. (2012b). The Social Practice of Sustainable Agriculture under Audit Discipline: Initial Insights from the ARGOS Project in New Zealand. Journal of Rural Studies. 28, 129-141. http://dx.doi.org/10.1016/j.jrurstud.2011.08.003

Carey, P., Moller, H., Norton, S., et al. (2010). A perspective on differences in soil properties between organic and conventional farming in dairy and sheep and beef sectors. Proceedings of the New Zealand Grassland Association, 72, 35-42

CEO Group, (2015). Building a performance focused culture and organisation. Website: Retrieved April 1, 2015, from http://www.ceo.co.nz/performance.php

Darnhofer, I., Fairweather, J., \& Moller, H. (2010). Assessing a farm's sustainability: Insights from resilience thinking. International Journal of Agricultural Sustainability, 8, 186-198. http://dx.doi.org/10.3763/ijas.2010.0480

Delate, K., Cambardella, C., Chase, C., \& Turnbull, R. (2015). A review of long-term organic comparison trials in the U.S. Sustainable Agriculture Research, 4(3), 5-14. http://dx.doi.org/10.5539/sar.v4n3p5

Fairweather, J., Hunt, L., Benge, J., et al. (2009a). New Zealand Farmer and Orchardist Attitude and Opinion Survey 2008: Characteristics of organic, modified conventional (integrated) and organic management, and of the sheep/beef, horticulture and dairy sectors. ARGOS Research Report 09/02.

Fairweather, J., Hunt, L., Rosin, C., \& Campbell, H., (2009b). Are conventional farmers conventional? Analysis of the environmental orientations of conventional New Zealand farmers. Rural Sociology, 74, 430-454. http://dx.doi.org/10.1526/003601109789037222

FAO (2013). Sustainability assessment of food and agriculture systems: SAFA Tool, beta version 2.1.50. Food and Agriculture Organization of the United Nations, Rome. Retrieved from http://www.fao.org/fileadmin/templates/nr/sustainability_pathways/docs/SAFA_Tool_User_Manual_2.1.50. pdf

Fukuda, Y., Moller, H., \& Burns, B. (2011). Effects of organic farming, fencing and vegetation origin on spiders and beetles within shelterbelts on dairy farms. New Zealand Journal of Agricultural Research, 54, 155-176. http://dx.doi.org/10.1080/00288233.2011.591402

Halberg, N., Panneerselvam, P., \& Treyer, S. (2015). Eco-functional intensification and food security: Synergy or compromise? Sustainable Agriculture Research, 4(3), 126-139. http://dx.doi.org/10.5539/sar.v4n3p126

Heckman, J. R. (2015). The role of trees and pastures in organic agriculture. Sustainable Agriculture Research, 4(3), 103-115. http://dx.doi.org/10.5539/sar.v4n3p51

Hole, D. G., Perkins, A. J., Wilson, J. D., Alexander, I. H., Grice, P. V., \& Evans, A. D. (2005). Does organic farming benefit biodiversity? Biological Conservation, $122, \quad 113-130$. http://dx.doi.org/10.1016/j.biocon.2004.07.018

Hunt, L., Fairweather, J., Rosin, C., et al. (2011). Doing the unthinkable: linking farmer's breadth of view and adaptive propensity to the achievement of social, environmental and economic outcomes. Proceedings $18^{\text {th }}$ International Farm Management Association Congress 'Thriving in a global market: innovation, co-operation and leadership', Methven, Canterbury, New Zealand. pp. 197-203. 
IFOAM (International Federation of Organic Agriculture Movements). (2005). Principles of organic agriculture. http://www.ifoam.org/about_ifoam/principles/index.html

IFOAM (International Federation of Organic Agriculture Movements). (2015). What is Organic 3.0? http://www.ifoam.bio/en/what-organic-30

Köpke, U., Athmann, M., Han, E., \& Kautz, T. (2015). Optimising cropping techniques for nutrient and environmental management in organic agriculture. Sustainable Agriculture Research, 4(3), 15-25. http://dx.doi.org/10.5539/sar.v4n3p15

Lindenmayer, D., Cunningham, S., \& Young, A. (2012). Landuse Intensification. Effects on agriculture, biodiversity and ecological processes. CSIRO Publishing.

MacLeod, C. J., Blackwell, G., \& Benge, J. (2012). Reduced pesticide toxicity and increased woody vegetation cover account for enhanced native bird densities in organic orchards. Journal of Applied Ecology, 49, 652-660. http://dx.doi.org/10.1111/j.1365-2664.2012.02135.x

Magbanua, F. S., Townsend, C. R., Blackwell, G. L., et al. (2010). Responses of stream macroinvertebrates and ecosystem function to conventional, integrated and organic farming. Journal of Applied Ecology, 47, 1014-1025. http://dx.doi.org/10.1111/j.1365-2664.2010.01859.x

Manhire, J., Moller, H., Barber, A., et al. (2012). The New Zealand Sustainability Dashboard: Unified monitoring and learning for sustainable agriculture in New Zealand. ARGOS Working Paper No. 8. $40+$ vi pages. Retrieved from www.argos.org.nz

Meadows, S. (2012). Can birds be used as tools to inform resilient farming and environmental care in the development of biodiversity-friendly market accreditation systems? Perspectives of New Zealand sheep and $\begin{array}{lllll}\text { beef farmers. Journal of } & \text { Sustainable Agriculture, } & 36, & \text { 759-787. }\end{array}$ http://dx.doi.org/10.1080/10440046.2012.672375

Millennium Ecosystem Assessment. (2005). Ecosystems and Human Well-being: Synthesis. Island Press. Washing, DC.

Moller, H., MacLeod, C., Haggerty, J., et al. (2008). Intensification of New Zealand agriculture: Implications for biodiversity, New Zealand Journal of Agricultural Research 51, 253-263. http://dx.doi.org/10.1080/00288230809510453

Moller, H., Wearing, A., Perley, C., et al. (2007). Biodiversity on kiwifruit orchards: the importance of shelterbelts. Acta Horticulturae 753, 609-618.

Niggli, U. (2015). Incorporating Agroecology Into Organic Research -An Ongoing Challenge. Sustainable Agriculture Research, 4(3), 149-157. http://dx.doi.org/10.5539/sar.v4n3p149

Norton, S., Lucock, D., Moller, H., \& Manhire, J. (2010). Energy return on investment for dairy and sheep/beef farms under conventional, integrated or organic management. Proceedings of the New Zealand Grasslands Association, 72, 145-150.

Pilati, A., Vanni, M. J., González, M. J., \& Gaulke, A. K. (2009). Effects of agricultural subsidies of nutrients and detritus on fish and plankton of shallow-reservoir ecosystems. Ecological Applications, 19, 942-960. http://dx.doi.org/10.1890/08-0807.1

Pretty J., Sutherland, W. J., Ashby, J., et al. (2010) The top 100 questions of importance to the future of global $\begin{array}{llll}\text { agriculture, International Journal of Agricultural Sustainability, } 8, & \text { 219-236. }\end{array}$ http://dx.doi.org/10.3763/ijas.2010.0534

Rosin, C., Perley, C., Moller, H., \& Dixon, K. (2008). For want of the social, was the biodiversity battle lost? On the need to approach social-ecological resilience through transdisciplinary research. New Zealand Journal of Agricultural Research, 51, 481-484. http://dx.doi.org/10.1080/00288230809510480

Rozzi, P., Miglior, F., \& Hand, K. (2007). A total merit selection index for Ontario organic dairy farmers. Journal of Dairy Science 90: 1584-1593. http://dx.doi.org/10.3168/jds.S0022-0302(07)71644-2

Sato, K., Bartlett, P., Erskine, R., \& Kaneene, J. (2005). A comparison of production and management between Wisconsin organic and conventional dairy herds. Livestock Production Science, 93, 105-115. http://dx.doi.org/10.1016/j.livprodsci.2004.09.007

Tuuli, M. M. (2012). Competing models of how motivation, opportunity, and ability drive job performance in project teams. In. Laryea, et al., (Eds). Proceedings of the 4th West Africa Built Environment Researchers 
(WABER) Conference (pp. 1359 - 1366). Abuja, Nigeria.

Todd, J. H., Malone, L. A., McArdle, B. H., Benge, J., Poulton, J., Thorpe, S., \& Beggs, J. R. (2011). Invertebrate community richness in New Zealand kiwifruit orchards under organic or integrated pest management. Agriculture, Ecosystems \& $\quad$ Environment, $141, \quad 32-38$. http://dx.doi.org/10.1016/j.agee.2011.02.007

Vaarst, M. (2015). The role of animals in eco-functional intensification of organic agriculture. Sustainable Agriculture Research, 4(3), 103-115. http://dx.doi.org/10.5539/sar.v4n3p103

Vogl, C. R., Kummer, S., Leitgeb, F., Schunko, C., \& Aigner, M. (2015). Keeping the actors in the organic system learning: The role of organic farmers' experiments. Sustainable Agriculture Research, 4(3), 140-148. http://dx.doi.org/10.5539/sar.v4n3p140

\section{Copyrights}

Copyright for this article is retained by the author(s), with first publication rights granted to the journal.

This is an open-access article distributed under the terms and conditions of the Creative Commons Attribution license (http://creativecommons.org/licenses/by/3.0/). 